\title{
UNA VENTANA PARA RESPIRAR. APUNTES PARA UNA GENEALOGÍA FEMINISTA DE LAS LUCHAS POR Democracia EN El PAís y EN LA CASA EN El Cono Sur EN LOS AÑOS 80.
}

\begin{abstract}
A WINDOW TO BREATHE. NOTES FOR A FEMINIST GENEALOGY OF THE STRUGGLES FOR DEMOCRACY IN THE COUNTRY AND IN THE HOUSE IN THE SOUTHERN CONE IN THE 8OS
\end{abstract}

\section{Maria Noel Sosa Gonzalez}

Resumen: En los años 80, durante los procesos de resistencia a las dictaduras y las luchas por la recuperación democrática en el Cono Sur hubo un resurgir del movimiento de mujeres y feminista con aspiraciones a una democracia más radical, capaz de alterar las jerarquías en el hogar y no solo derrocar el autoritarismo y el terrorismo estatal. La consigna "Democracia en el país y en las casas" de las feministas chilenas da cuenta de esta renovada apuesta política. Me propongo esbozar una genealogía de lo que ha supuesto la misma como elemento aglutinador de luchas y como apertura política, asumiendo que en el ciclo de lucha contra las dictaduras y por la recuperación democrática en el Cono Sur hubo una fuerte presencia de organizaciones feministas y de mujeres, cuyas especificidades y aportes suelen quedar relegados en los registros históricos. La apuesta es trabajar desde el contexto de los diferentes países, pero profundizar en cómo la misma fue cobrando sentido en Uruguay.

\footnotetext{
* Estudiante de Doctorado en Sociología, Benemérita Universidad Autónoma de Puebla. Docente del Servicio Central de Extensión y Actividades en el Medio, Universidad de la República, Montevideo, Uruguay.

Contacto: noel.sosa.gonzalez@gmail.com

Fecha de recepción: 1511 18; 2a. versión: 2904 19; Fecha de aceptación: 030719.
}

(cc) BY-NC-ND Páginas 73-98 
Palabras clave: feminismo, democracia, organización política, genealogías feministas, cono sur.

Abstract: In the 80s, during the processes of resistance against dictatorships and in the struggles for democratic recovery in the Southern Cone there was a resurgence of women's and feminist movements with aspirations of a more radical democracy, capable of altering hierarchies at home and not just overthrowing authoritarianism and state terrorism. The slogan "Democracy in the country and in the houses" of Chilean feminists attests this renewed political commitment. I propose to sketch a genealogy of what it has meant as a unifying element of struggles and as a political opening, assuming that in the cycle of struggle against dictatorships and for the democratic recovery in the Southern Cone there was a strong presence of women and feminist organizations, whose specificities and contributions are often relegated in historical records. The bet is to work from the context of the different countries, but to deepen in how it gradually made sense in Uruguay.

Keywords: feminism, democracy, political organization, feminist genealogy, southern cone.

En términos biológicos nacemos solo una vez —llegamos al mundo desde el canal de parto o extraídas ${ }^{1}$ vía abdominal desde el útero materno-- pero en términos simbólicos los nacimientos pueden ser muchos. "Aquí estamos, hemos vuelto a nacer" 2 fueron las palabras colectivas con las que nombramos nuestra vivencia sobre un nuevo tiempo de lucha feminista en Uruguay. A la par, mientras nos convocamos "a poner el movimiento en movimiento" afirmamos que éramos diversas y "todas paridas de mujer" ${ }^{3}$. En estos mismos

${ }^{1}$ En este texto escribo en femenino, por mi ser mujer y porque hablo mayoritariamente de mujeres. No lo hago en términos biologicistas restrictivos, sino desde una mirada crítica y como parte de la afirmación de la categoría mujer, como modo específico de explotación y opresión y por tanto como experiencia histórica. Sin excluir por ello otras experiencias de cuerpos feminizados o disidentes, a los que también se ha desvalorizado simbólicamente. Asimismo, lo hago de manera provocativa para llamar la atención sobre el canon androcéntrico del lenguaje, por lo que al hablar en modo general de hombres, mujeres y personas trans procuraré a nivel general hablar de persona/as, por tanto su conjugación será también en femenino.

${ }^{2}$ Esta frase quedó registrada en las palabras dichas por algunas de las integrantes del colectivo Minervas, del que formo parte. Puede encontrarse el texto completo en Migliario, Menéndez y Blanco (2014).

${ }^{3}$ Declaración del Primer Encuentro de Feminismos del Uruguay. Montevideo, noviembre 2014. 
años fuimos encontrando referencias de que, en la transición democrática en Uruguay, miles de mujeres se organizaron en espacios propios dentro de diferentes organizaciones sociales, en espacios académicos o en grupos barriales autónomos en varias ciudades del país. Desde allí ensayaron otras formas de lo político y se asumieron feministas desde el movimiento popular. Esta búsqueda personal y colectiva, estas pistas y el haber encontrado un afiche de la convocatoria a la marcha del 8 de marzo de 1985 fueron el puntapié que motivó mi tesis doctoral, titulada Las mujeres quisimos y queremos cambiar la vida. Palabras propias sobre los despliegues y limites de las luchas de las mujeres en Uruguay (2014/1979-1995).

Sobre este trabajo de investigación -que está aún en curso- es que compartiré algunos avances en este texto ${ }^{4}$. Me propongo esbozar una genealogía a partir de la consigna "Democracia en el país y en las casas", entendiendo que la misma fue un elemento aglutinador de luchas, en las que confluyeron aquellas por democracia a nivel general, junto a los reclamos feministas. Asimismo dicha consigna permitió confluir a las organizaciones de mujeres junto a las organizaciones feministas y refleja la apertura política que estas luchas significaron.

En el ciclo de lucha contra las dictaduras y por la recuperación democrática en el Cono Sur hubo una fuerte presencia de organizaciones feministas y de mujeres, cuyas especificidades y aportes suelen quedar relegados en los registros históricos. La apuesta es trabajar desde el contexto de los diferentes países, pero profundizar en cómo esta consigna fue cobrando sentido en Uruguay. Los aportes de la feminista chilena Julieta Kirkwood estarán a lo largo del texto, por su vinculación a la consigna y por sus desarrollos teóricos.

A nivel general abordo especialmente las luchas feministas, aunque esto no supone asumir que el patriarcado es la estructura central de la dominación como antes lo era la clase, sino pensar en estas redes imbricadas, sus matrices múltiples y las raíces históricas compartidas que conforman la modernidad capitalista patriarcal y colonial (Gutiérrez Aguilar; Sosa y Reyes, 2018). De igual modo, analizar las prácticas de resistencia y lucha que se les han opuesto a tal forma es relevante no solo para el feminismo, sino para la lucha social en general.

\footnotetext{
${ }^{4}$ Este texto nace del intercambio con las compañeras del seminario "Feminismos en América Latina" a cargo de la Dra. Patricia Castañeda. El mismo fue dictado en la UNAM en el ańo 2018. Agradezco los diálogos allí mantenidos a todas las participantes y especialmente a Sandra González por las conversaciones sobre nuestras tesis y por la lectura atenta de este manuscrito.
} 

para una genealogía feminista...

Nombro luchas de las mujeres y luchas feministas de forma decidida y en sentido amplio, porque hablar sólo de luchas feministas en un sentido estricto puede dejar por fuera algunas de las organizaciones de mujeres no feministas. En varios momentos históricos ha habido mujeres en lucha que, por diversas razones, no necesariamente se autodenominaban feministas, aunque en sí mismas están cuestionando el orden de dominación sexo-genérico. Muchas de ellas devinieron luego en mujeres o colectivos que se nombraron a sí mismas feministas, pero eso no sucede ni en todos los casos, ni de forma lineal, ni en el mismo tiempo de la lucha. En caso de cerrar categóricamente el análisis a las luchas feministas se corre el riesgo de dejar fuera organizaciones como Madres de Plaza de Mayo, en la Argentina de la última dictadura cívico-militar, las Mother Reclaiming Our Children en Estados Unidos durante los años 80, a las Maes do Maio del Brasil de los últimos años o los cientos de luchas anti extractivas a lo largo y ancho de América Latina que están sucediendo ahora mismo. Decir "luchas de las mujeres" me permite nombrar y recoger los fértiles

Figura 1. Marcha 8 de marzo 1985. Montevideo, Uruguay.

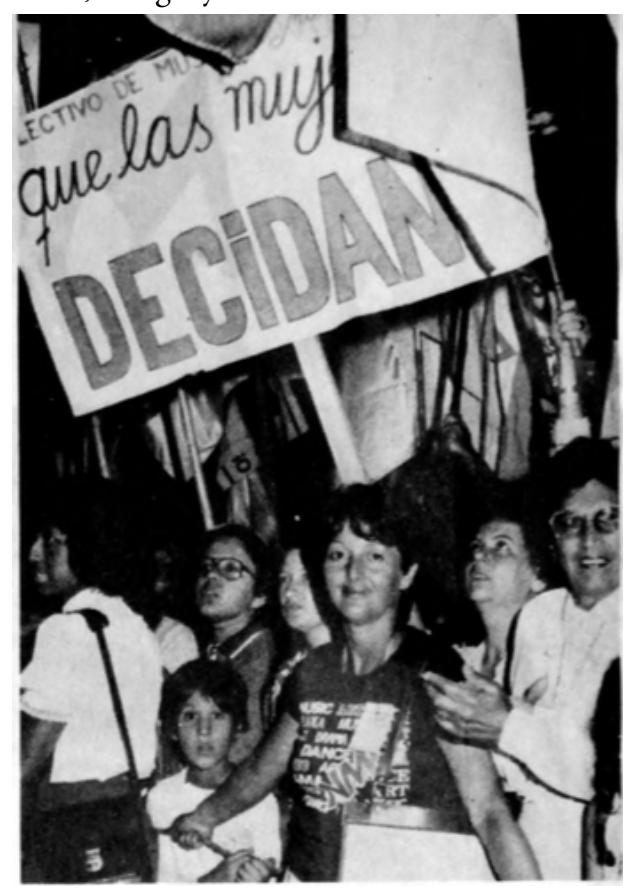

Fuente: Cotidiano Mujer, Año 1, Numero 1, p.2 

para una genealogía feminista...

aportes de diversas mujeres en lucha, asumiendo que estas causas preceden y exceden a los feminismos aunque también se supongan mutuamente.

Para el caso de Uruguay, algunas de estas organizaciones, que aunque en su discurso explícito no siempre se asumieron como feministas, se componían por mujeres que en el proceso de participación llegaron a asumirse como tales. $\mathrm{Al}$ mismo tiempo, en varios grupos de mujeres se llevaban a cabo prácticas feministas. Es en tal sentido que se habla de luchas de mujeres y feministas. Insisto en tomar los diferentes feminismos, en sentido plural, con sus diversas matrices y énfasis porque que cada lucha va posibilitando criticas teóricas y aperturas políticas que responden a un tiempo de rebelión en concreto que nos nutre y nos inspira.

En la reapertura democrática del Cono Sur, las mujeres y feministas imaginaron y lucharon por una democracia que fuera más allá de los límites institucionales y de la separación público-privado. En medio de la represión y la censura, el feminismo supuso una ventana para respirar ${ }^{5}$, especialmente para dejar entrar aires nuevos a la izquierda política y al movimiento popular. Sin embargo, para muchas de nosotras nacidas ya en democracia, los lazos con las historias de luchas anteriores, las imágenes de estas otras mujeres y sus relatos y experiencias no fueron la palabra con la que aprendimos a hablar. Entiendo que las palabras que aquí siguen son parte de los esfuerzos colectivos por la construcción de nuestros linajes feministas, que desandan el sentimiento de orfandad y la ruptura en la transmisión intergeneracional a los que nos hemos enfrentado.

Señalo que se trata de un esbozo de genealogía feminista porque la misma está aún en proceso. Me interesa partir de la propuesta de genealogías feministas de Restrepo (2016) como método y como apuesta política. En diálogo con las genealogías en sentido foucaultiano, pero desde los aportes de los feminismos, las genealogías feministas (Restrepo, 2016) nos permiten entender un tipo específico de relaciones de poder -las que se establecen entre hombres y mujeres-, pero a la vez son una apuesta por los vínculos entre mujeres y el rescate de su presencia en la historia. No es únicamente un recorrido por los hechos históricos sino una búsqueda por las condiciones de posibilidad de tal consigna, un rastreo de la apuesta política que suponía y de los elementos que aún laten para el presente de lucha feminista actual. Recupero en este sentido el libro Nacida de mujer (Rich, 1978) para pensar la revalorización

${ }^{5}$ Tomado en referencia a una forma de pensar lo que supone el feminismo y su desafío a la cultura dominante de Margarita Pisano (2004, p. 64). 
de la creación femenina y abrir posibilidades de otros modos de entender las relaciones madre-hija, especialmente en el plano simbólico y político. Si las genealogías patriarcales son parte del andamiaje de dominación (Restrepo, 2016) y a nivel simbólico tal estructura de mediación nos hace mirar al padre como el verdadero autor de la vida (Rivera Garretas, 1997), las genealogías feministas nos quitan del lugar de orfandad -en este caso política- al que se nos expone permanentemente. No se trata de una mirada esencialista o ingenua de lo femenino, pero sí es una revisión que quiere reconocer una experiencia histórica anclada en unos cuerpos específicos, en tanto tales experiencias de otras se entretejen con las nuestras, son otro modo de un partir de sí, para no quedarse en sí y ser con otras (Menéndez, 2018) como un intento de no separar nuestro cuerpo femenino de las luchas que damos e ir creando mundos nuevos.

\section{El Manifiesto Feminista y la consigna "Democracia en el país y en las casas"}

Las aspiraciones de una democracia más radical, capaz de alterar las jerarquías en el hogar y no solo derrocar el autoritarismo y el terrorismo estatal sudamericano de los años 80 se cristalizaron en la frase "Democracia en el país y en las casas". Esta, de las feministas chilenas durante la dictadura de Pinochet, rápidamente circuló -incluso con algunas variantes- por el resto del Cono Sur. A través de estas palabras las mujeres sostuvieron una apuesta política renovada, en tanto resistieron a las dictaduras y lucharon por recuperar la democracia desde diversos espacios y en varios de los frentes del movimiento popular. Lo hicieron desde un lugar específico, el de mujeres. No se trataba de un reclamo sectorial, sino que a partir de su experiencia histórica y corporal se atrevieron a cuestionar todas las jerarquías, tensando la supuesta condición de igualdad entre mujeres y hombres que conformaba el imaginario democrático y político previo.

Fueron los aportes de Julieta Kirkwood ${ }^{6}$ y Margarita Pisano ${ }^{7}$, ambas feministas, los que plasmaron desde sus palabras un sentido común que estaba

\footnotetext{
${ }^{6}$ Socióloga y politóloga. Investigadora de FLACSO. Es de las mayores referentes del feminismo chileno y de los debates feministas sobre la democracia. Fallece en 1985. Su texto más conocido es Ser politica en Chile: las feministas y los partidos (1986), compilación póstuma de materiales previamente publicados por FLACSO. Fue creadora del Círculo de Estudios de la Mujer (1979-1983).

${ }^{7}$ Arquitecta y militante feminista chilena. Creadora de Casa de la mujer y luego de La Morada. Integrante de "Las cómplices" y referente del feminismo autónomo en los años 90. En Un cierto
} 
siendo desplegado. Pero ¿dónde surgió tal consigna?, ¿cómo fue aconteciendo su multiplicación?, ¿cómo se entendió entonces?, ¿quiénes fueron las otras mujeres desde las que la idea fue germinando?

Los procesos de resistencia al terrorismo estatal y la urgencia por la recuperación de una democracia que frenara la máquina de tortura, desaparición y muerte son parte de la historia común del Cono Sur. Las últimas dictaduras cívico-militares son muy cercanas en tiempo y características en Argentina (1976-1983), Chile (1973-1990) y Uruguay (1973-1985). Brasil también comparte buena parte de los rasgos aunque su proceso se inició casi una década antes (1964-1985). En toda América Latina estos son los años en los que se da inicio al proceso de liberalización de la economía, impuesta con la instalación de las dictaduras y consolidada en los ańos noventa (Quijano, 2004). Los países del sur también comparten el resurgir del movimiento de mujeres y/o feminista, que fue capaz desde sus primeros pasos de trascender los partidos políticos y desde allí resistir a las dictaduras y dar sustento a otras las luchas.

El contexto de la lucha por la democracia se nutrió de una fuerte participación de las mujeres en la militancia social (partidos políticos, sindicatos, gremios estudiantiles) y del encuentro en el exilio con las luchas y los debates feministas de otras latitudes. Desde finales de los años 70 surgieron grupos de mujeres nuevos, tanto en clave de derechos humanos, ollas populares ${ }^{8}$ o de definición feminista específica. Este resurgir del movimiento de mujeres y/o feminista se sumó y dedicó mucha de su energía a la recuperación de la democracia, mientras politizaba el malestar de las mujeres en lo privado. En lo sucedido en los años 90 y las derivaciones de lo que se ha llamado como corriente institucional y autónoma también tienen su implicación los debates sobre la forma de lo político, el relacionamiento con los partidos políticos, sus posibilidades y los límites de la institucionalidad democrática.

En el marco de la consigna hay un rechazo a la política tradicional desde una búsqueda por los contenidos de la democracia y su revalorización. Las que venían de las luchas y de las organizaciones de la izquierda traían consigo los

desparpajo (1996) y en Una historia fuera de la historia, de Pisano y Franulic (2009) se recoge su biografía y sus principales aportes al debate feminista.

${ }^{8}$ Se denomina ollas populares a comedores comunitarios u otros espacios en los que se resuelve de manera comunitaria la alimentación. Es una actividad muy popular en el Cono Sur, que se pone en práctica en algunas instancias como huelgas y ocupaciones de espacios de trabajo o en barrios populares, especialmente durante las crisis económicas. 
debates y las criticas clásicas a la democracia "liberal y burguesa" y ampliaron los anhelos de una democracia como práctica política general, sus espacios concretos y su necesaria ampliación a la vida toda.

Lo que se conoce como feminismo de la segunda ola en Europa y Estados Unidos tuvo un derrotero diferente en América Latina, dado el contexto de represión, pero es en la transición de los años 80 y en este contexto que cobra fuerza la idea de que lo personal es político, que acuñara en el norte Carol Hanish. Esta consigna del norte tuvo en el sur más arraigo desde la idea de "lo privado es político" (Integrante Plemuu, comunicación personal, 15 de febrero 2018) y desde la propia consigna sobre democracia en todas partes. Desde este punto de partida se logra unir y potenciar las miradas sobre el patriarcado con el contexto autoritario y de terrorismo estatal, y se incluye la mirada al interior de los movimientos sociales y del propio movimiento feminista.

La consigna "Democracia en el país y en la casa" aparece escrita en el Manifiesto Feminista: demandas feministas a la democracia, publicado en 1983, y en breve se volvió lema de las movilizaciones en la calle (Kirkwood, 1986). Con los años fue incluso ampliándose en "Democracia en el país, en la casa y en la cama" (Pisano y Franulic, 2009). Es una consigna que se ha ido modificando en los escenarios políticos, pero que sostiene y relanza la denuncia de la falsa separación público-privado y lo que ello supone para las mujeres e insiste en denunciar todos los espacios de jerarquía patriarcal.

El Manifiesto Feminista reunía la mirada de las mujeres sobre la democracia por venir, no sólo eran las demandas feministas a la democracia, sino un modo distinto de entender la democracia misma. Margarita Pisano y Julieta Kirkwood eran amigas, habían compartido espacios en el Círculo de Estudios de la Mujer y venían ambas, junto a muchas otras, de realizar talleres en los barrios, de problematizar la ciudad y su lugar de mujeres. Todas ellas no solo lograban escabullirse de la represión para hablar de sexualidad, de la historia de las mujeres y de cómo habían vivido estos años de terror, sino que juntas lograron empezar a denunciar públicamente las torturas y comenzaron a rearmar el movimiento feminista en Chile. El mismo manifiesto se venía pensando hacía casi un año y tenía la pretensión de volantearse en las calles, de seguir convocando a otras mujeres.

Julieta Kirkwood fue una de las feministas que dio sustento conceptual y difusión a la consigna, desarrollando en sus textos la apuesta de las mujeres de no solo luchar contra la dictadura, sino también con la forma en que esta 

para una genealogía feminista... reforzó el sistema patriarcal, cuestionando las lógicas internas de los partidos y otras organizaciones políticas. De la mano están sus aportes sobre los Figura 2. Manifiesto Feminista, Chile, 1983

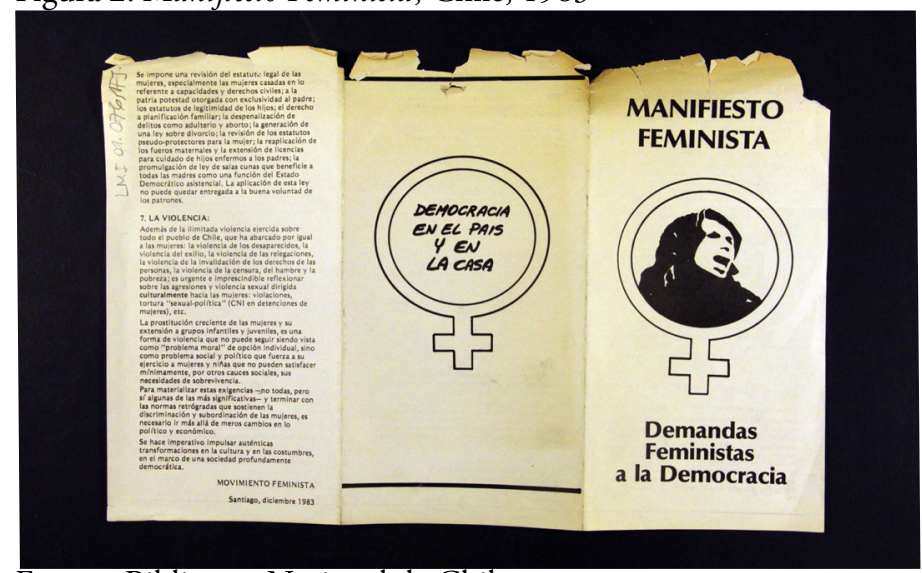

Fuente: Biblioteca Nacional de Chile

"lugares de enunciación” y los "nudos de la sabiduría feminista”, que también trabajaban en términos de la democratización de la palabra, el saber, y el lugar de las mujeres en la producción de teoría.

Fue también en estos años que se realizaron fértiles intercambios entre feministas de Latinoamérica y el mundo, siendo los Encuentros Feministas de Latinoamérica y el Caribe (EFLAC) el lugar privilegiado para volcar experiencias, reflexiones y planificar acciones colectivas. La propia Kirkwood los señala como "ese gigantesco estar juntas las mujeres" (1986), un espacio de despliegue feminista pero también de tensión entre diferentes trayectorias y posturas.

Desde estos espacios de autonomía es que se realizan, asimismo, ciertas provocaciones y debates con el mundo político masculino y sus cánones teóricos. Hay una preocupación muy fuerte por el debate sobre la clase social que el feminismo sacude y renueva. Como fue señalado, varias de estas mujeres venían de militancias múltiples y tenían una preocupación insistente por la relación del feminismo con el movimiento popular y la izquierda. Desde su experiencia concreta reclaman que estos espacios no habían reparado en las reivindicaciones específicas de las mujeres o que cerraban el análisis de la explotación/dominación. En ese contexto, fue la misma Kirkwood (1986) 
quien señaló que la clase ni agota ni explica todas las dominaciones y el feminismo es también revolución. En sus aportes teóricos se preocupa por mostrar el lugar de las mujeres en la historia de lucha del país, para discutir sobre la invisibilización y el silenciamiento del que también la izquierda social y política fue cómplice. La noción de igualdad, tan pilar de la democracia, fue asimismo señalada como "mito" y como una imposibilidad teórica y fáctica (Kirkwood, 1986).

\section{Tiempo de mujeres. Nuevos espacios, nuevos debates}

Las movilizaciones no solo fueron desde el feminismo, sino en muchos casos como movimientos de mujeres. Julieta Kirkwood señala: "Quisiera decir feministas, pero empiezan a moverse muchas mujeres (...)” (1986: pp. 18). Las mismas surgen en el contexto de aspiración a recobrar la democracia, pero con un fuerte énfasis en el lugar y la participación de las mujeres. Desde esta amplitud, esta confluencia hace posible ampliar los debates feministas y generar una movilización de mujeres amplia.

En Chile, el movimiento de mujeres y feminista resurge y se revitaliza en la lucha contra la dictadura, se va armando desde las mujeres que luchan en clave de defensa de los derechos humanos, desde las ollas populares y otras medidas contra la "carestía económica", así como desde las luchas feministas denominadas como tales. Bajo el signo del feminismo popular, nacieron MUDECHI $83^{9}$ (Mujeres de Chile 83) y otras organizaciones que compartían el rechazo a los modos tradicionales de hacer política. En 1983, en las Jornadas Nacionales de Protesta se comienza a popularizar la consigna porque daba cuenta de estos hilos en común. Se trataba de un modo que cuestionaba la rigidez de las estructuras de los partidos y las jerarquías en los roles de las organizaciones. En esos años se realizaban talleres sobre trabajo doméstico, maternidad, violencia, democratización de la vida familiar, de la escuela y del país. Varias de las grandes manifestaciones que marcaron la reapertura democrática fueron organizadas por estas mujeres (Tessada Sepúlveda, 2013).

En Argentina fue precisamente un grupo de mujeres el que enfrentó con mayor contundencia al terrorismo estatal, politizando un lugar reservado como cautiverio: las Madres de Plaza de Mayo, y luego también las Abuelas, han sido toda una referencia. Pero, aquellos de la transición democrática también fueron años de vitalidad para el feminismo. Desde los inicios de la

\footnotetext{
${ }^{9}$ La nominación se enlaza en tributo al MEMCH (Movimiento de Emancipación de las Mujeres Chilenas), la principal agrupación sufragista chilena de principios del siglo XX.
} 
década de los 80 se fundaron agrupaciones nuevas y se realizaron demandas específicas como la reforma de la patria potestad. También surgieron grupos de "toma de conciencia" o de "concienciación". De forma similar a lo que sucedió en la región, buscaron modos de articulación y crearon la "Multisectorial de Mujeres", un espacio transversal en el que confluyeron mujeres diversas, de las que se componían los diversos flujos de lucha de ese tiempo: sindicalistas, amas de casa, mujeres de los partidos políticos, de las luchas en defensa de los derechos humanos (Tarducci y Rifkin, 2010).

En Uruguay, el 8 de marzo de 1985, las mujeres uruguayas se congregaron bajo la consigna "Las mujeres no solo queremos dar vida, queremos cambiarla". Aunque hay acuerdo entre las investigadoras feministas en este tiempo fértil de la luchas de las mujeres, y del que 1984 fue un año clave, se señalan diferentes momentos en los que el mismo movimiento cobró visibilidad (Johnson, 2000; Sapriza, 2003). Del año 1984 se enfatizan tres fechas relevantes por sus acciones públicas y sus posibilidades de articulación: el 26 de enero de 1984, el 8 de marzo de 1984 -conocido como el "8 de marzo de la rosa" por la actividad en el Centro de Obreros de Alpargatas- y la masiva manifestación de frenteamplistas del 15 de noviembre (Sapriza, 2003). Todas estas fechas fueron de una creciente actividad pública, que tuvo una de sus mayores expresiones en la marcha del 8 de marzo de 1985. La investigadora feminista Sapriza (2003) señala asimismo la marcha del Frente Amplio (FA) que se realizó a una semana de las elecciones nacionales de 1984 y en la que se estima concurrieron más de 150.000 personas, como otro hecho relevante para el movimiento de mujeres, porque mayoritariamente las mujeres la organizaron y porque para muchas fue la primer salida de las mujeres sin pedir permiso (Sapriza, 2003). Es allí que aparece con fuerza en carteles la consigna "Democracia en la casa”, pese a que tal consigna fue rechazada por el comité de campaña del FA, porque no querían ser acusados de inmiscuirse en la vida doméstica ni invadir la privacidad del hogar (Johnson, 2000).

Estas movilizaciones dan cuenta de la gesta, en años anteriores, de un movimiento con una dimensión propia más allá de los partidos y de los espacios políticos existentes a nivel general. En Uruguay, a partir de 1979 las mujeres comenzaron a formar espacios propios y, en todos esos años, produjeron experiencias novedosas (Cardoso, 2014; Giorgi, 2015; Johnson, 2000; Sapriza, 2001, 2003 y 2014). El primero de estos espacios es el Grupo de Estudios sobre la Condición de la Mujer Uruguaya (Grecmu) creado en 1979, que nucleaba a 
investigadoras que no podían desarrollar tareas académicas en la Universidad de la República (Udelar), puesto que esta última estaba intervenida. En 1983 se crea una de las organizaciones paraguas que tendrá mayor protagonismo en esos ańos, el Plenario de Mujeres del Uruguay (Plemuu). De la mano con esta organización hubo también un crecimiento de organizaciones similares en el resto del país, que tiene como hecho relevante la realización en 1985 del Primer Encuentro de Mujeres del Interior, en la ciudad de Melo, dinamizado por Las Paulinas, colectivo de mujeres de esa misma localidad. Entre 1984 y 1985 se van creando otras organizaciones feministas, que perduran hasta la actualidad, como el Instituto Mujer y Sociedad, Cotidiano Mujer y Mujer Ahora (Cardozo, 2014). Se crean dos casas de la mujer: Casa María Abella y Casa de la Mujer de la Unión. También, en ese período se crea la Comisión de mujeres del Pit-cnt, vinculada al mundo sindical. También están la Federación Uruguaya de Amas de Casa (Fuadec), la Comisión de Mujeres Uruguayas y la Unión de Mujeres Uruguayas, que tienen menor duración y relevancia.

Hubo también un proceso fértil para el feminismo de anclaje barrial y popular (Tornaría, 1986) que germinaba desde hacía varios años. Se realizaron grupos barriales de mujeres y, al igual que en Chile, fueron las mujeres quienes desempeñaron un papel fundamental en las estrategias de sobrevivencia de los sectores populares para enfrentar las dificultades económicas, incluso cuando la dictadura implicó un ingreso masivo de las mujeres al mercado de trabajo, lo que conllevó el doble esfuerzo de asumir las tareas domésticas y las laborales (Sapriza, 2003).

A partir del plebiscito de 1980 hubo organizaciones de mujeres, principalmente en la órbita de los derechos humanos. En 1986, luego de que el parlamento aprobó la Ley de Caducidad de la Pretensión Punitiva del Estado, que imposibilitaba juzgar a los militares por los crímenes cometidos, la organización Madres y Familiares de Detenidos y Desaparecidos Uruguayos inició una campaña para anular la ley a través del mecanismo del referéndum. Fueron precisamente tres mujeres las que presidieron la Comisión Nacional pro Referéndum y organizaron la tarea.

No todas las mujeres organizadas se autodenominaban feministas y hubo, entre las organizaciones feministas y de mujeres, diferencias y tensiones en este sentido. Pero al igual que en el resto de América Latina, supuso un gran "ensayo político" (Kirkwood, 1986) que partió del cuestionamiento de sus lugares en la izquierda y de una profunda mirada al mundo de la familia y el hogar. Se 
esfuerzan por nombrar y denunciar el autoritarismo en las familias que supone la estructura patriarcal, de decir que en la familia hay oprimidos que oprimen y que la familia proletaria se parece demasiado a la burguesa (Kirkwood, 1986, p.39). Señalan con agudeza que el autoritarismo de la dictadura recurre a los autoritarismos subyacentes en la sociedad para reafirmarse.

Sobre este tiempo de creación, de encuentro, de estar entre mujeres, Kirkwood señala como elementos novedosos las modalidades organizativas y los nuevos modos del lenguaje. Frente al autoritarsmo, la "rebeldía femenina" no solo denuncia y enfrenta la represión, sino que forma organizaciones diferentes a las que ella nomina como comunitarias, solidarias y/o reivindicacionistas, y que señala como espacios con una profunda democracia interna. Estas nuevas formas se nutren de la negación del autoritarismo en la experiencia vital, en el caso de las mujeres en resistir a la figura de autoridad masculina (Kirkwood, 1986). Se cuestiona el vanguardismo político y se revaloriza como nuevos espacios políticos a la familia y el barrio, como espacios de política no abstracta, sino concreta (Tornaría, 1986, Kirkwood, 1986).

En los textos escritos en ese momento se señala la aspiración a un movimiento de mujeres en forma de red, con múltiples grupos, de débil estructuración y sin jerarquías, que apunte a la coordinación con base en pautas comunes sin centralización, pero con respeto y solidaridad. Se abre la posibilidad de pensar que lo político no se reduce a la lucha por el poder del estado, sino a pensar que existen relaciones de poder a lo largo y ancho del tejido social (Tornaría, 1986, p. 56). Es por ello que la estructura de Plemuu en ese entonces buscaba ser flexible y tenía fuerte interés en establecer relaciones horizontales entre sus integrantes (Johnson, 2000). En la misma línea evitaban establecer jerarquías, atendían a las posibilidades de cada quien y señalaban que las decisiones se tomaban por consenso. Tenían una red organizada entre los grupos, según lo descrito sobre sus reuniones y plenarios, pero a la vez había un desborde de diversas mujeres que participaban desde los espacios barriales. Esta estructura abierta y flexible convivía, sin embargo, con una tendencia de institucionalización y formatos más rígidos de dirección que cobraron mayor nivel de tensión cuando la democracia ya empezó a andar y se reactivaron los espacios de otras organizaciones sociales y políticas.

En el caso uruguayo, la consigna del 8 de marzo de 1986: "No habrá un nuevo Uruguay sin la plena participación de la mujer" (Cardozo, 2014, Cotidiano Mujer, 1986b) siguió resonando en los años posteriores al retorno 
de la democracia institucional, insistiendo en que sin las mujeres no puede haber plena democracia. Los aportes de Julieta Kirkwood y Margarita Pisano, desde su militancia feminista, cristalizaron con sus palabras un sentido común que estaba siendo desplegado: la democracia liberal no alcanzará, se necesita democracia en todas partes. Desde la vida cotidiana se vuelve a denunciar la falsa separación público-privado y lo que ello supone para las mujeres, se insiste en denunciar en todos los espacios la jerarquía patriarcal (Tornaría, 1986, Giorgi 2015) que tan costosa ha sido para las mujeres: "Lo cotidiano de la mujer que estaba adentro de la casa que estaba tan sometida y estaba tan deprimida que le impedía saber de que tenía la posibilidad de cambiar cosas" (Integrante Plemuu, comunicación personal, 8 de febrero 2018).

Las referencias a Julieta Kirkwood aparecen fácilmente, porque aunque se trataba de una feminista chilena, sus aportes teóricos y su constante esfuerzo por ir escribiendo y ordenando los sentidos de las luchas tuvieron repercusiones en Uruguay: "Julieta Kirkwood era un personaje con la que nos encontrábamos. (...) para nosotros fue como una revelación las cosas de Julieta de lo privado es político" (Integrante Plemuu, comunicación personal, 8 de febrero 2018). Fue ella una de las que más trabajó al respecto, imprimiendo una tónica propia dado el contexto de América Latina. La idea de que "Lo personal es político" era herencia de luchas anteriores, pero fue cobrando nuevos sentidos. En varios documentos de uno de los espacios de prensa de la época se señalan los encuentros con las feministas chilenas y su consigna, y lo que ello permitía para pensar la situación local. Estos encuentros se daban tanto en las lecturas de los textos de Kirkwood, en los EFLAC y en visitas que las chilenas realizaban al país (Cotidiano Mujer, 1986a; 1986b; 1987).

La apuesta era entrar en el mundo de los hombres, pero transformarlo y para ello estaban ensayando el encontrarse entre ellas, reconocerse, identificarse, tener tiempos y espacios propios que no supusieran ser base patriarcal de nuevas organizaciones. Esta defensa de la autonomía feminista, el reclamo por ser "sujetos de su rebeldía" no destruye ni invalida la aspiración de cambio social político global. No se trata de incorporarse a una política "ya en marcha”, sino hacer política desde mujeres y sus experiencias, de unir la lucha en clave clasista y antipatriarcal sin sacrificar, sin priorizar (Kirkwood, 1986).

El movimiento de mujeres, al enfatizar el asunto de la separación públicoprivado, no solo debate con la democracia liberal, sino que atrae la atención 
a mirar las otras opciones democráticas que pueden entenderse como más radicales (Phillips, 1996). Desde estos espacios de autonomía es que se realizan también ciertas provocaciones y debates con el mundo político masculino y sus cánones teóricos. Una de ellas es denunciar una y otra vez que las mujeres no tenemos el mismo tiempo para participar de los espacios políticos por hacernos cargo de las tareas domésticas y de cuidado, es decir, señalar la exclusión de las mujeres del mundo de la política institucional dada la división sexual del trabajo. Esta situación no había sido considerada como sí lo eran otras desigualdades observadas con más atención por la izquierda. Luego del debate sufragista parecía que las diferencias habían desaparecido, pero las mujeres volverían a señalar una de las falacias de la democracia: el individuo, la base de la democracia liberal desde su lugar como ciudadano, es siempre un hombre. A la par van realizando otra de las críticas comunes, evidenciando lo obvio: que en los cargos hay más hombres, más allá de los años que hacía de la conquista del voto, es decir la incorporación formal de las mujeres, poniendo en tela de juicio la noción misma de representación (Phillips, 1996). La noción de igualdad, pilar fundamental de la democracia, fue asimismo señalada como "mito" y como imposibilidad teórica y fáctica (Kirkwood, 1986). Al respecto, en sus desarrollos sobre la relación del feminismo con la democracia, Phillips (1996) señala las trampas de la clave de la igualdad al decir: "cuando hombres y mujeres son tratados igual es porque las mujeres son tratadas como si fueran hombres; cuando hombres y mujeres son tratados de modo diferente, el hombre es la norma respecto de la cual la mujer es peculiar, carente y diferente" (p. 46)

Hay una apuesta por una democracia participativa, cuestionando la separación dirigente-dirigidos en su embestida contra todas las jerarquías, se trabajaba buscando evitar las "estrellas" del feminismo ${ }^{10}$ a la par que buscaban democratizar la vida cotidiana y los otros espacios en los que participaban. Es un movimiento similar al del movimiento feminista de la segunda ola en el norte, también muy sensible a las relaciones de dominación en su interior (Phillips, 1996). Desde los grupos o espacios solo de mujeres empezaron a también a cuestionarse a sí mismas, a mirar su lugar de mujeres realizando una política masculina y lo que esto puede suponer en términos de lenguaje y forma organizativa.

\footnotetext{
${ }^{10}$ En referencia a lo planteado por Jo Freeman (1975), en su debate sobre el problema de no establecer referencias claras sobre la estructura y los riesgos que eso puede suponer para que existan figuras referentes pero no explícitas que pueden llevar a "la tiranía de la falta de estructuras".
} 


\section{Uruguay: los espacios propios de las amas de casa}

En Uruguay, como fue señalado, hubo en esos años un momento fértil para el feminismo. Fueron creadas nuevas organizaciones que aportaron a la lucha y a los debates y conforman los hilos de la genealogía feminista. En este trabajo me interesa detenerme en uno de estos espacios, específicamente de mujeres, que abordaron y dinamizaron todos estos planteamientos: se trata de Plemuu (Plenario de Mujeres del Uruguay), espacio que nucleaba a las amas de casa y desde donde se pensó fuertemente sobre el espacio de la casa y la familia. Asimismo es relevante al respecto del debate sobre la democracia, porque fueron ellas quienes convocaron y dedicaron tiempo y esfuerzo en lo que se conoce como los documentos de "la condición de la mujer" de la Concertación Nacional Programática (Conapro). Se trató de una organización de mujeres que inicialmente no se autodenominaba feminista, aunque varias de sus integrantes fueron nombrándose feministas con el tiempo y existe una publicación que se titula Nuestro feminismo, un proyecto de vida (Tornaría, 1986). Me interesa abordar la experiencia de este grupo por ser un espacio de organización novedoso, propio de mujeres, por fuera de los espacios tradicionales del movimiento popular, por sus actividades barriales y su enlace con varias ciudades del interior del país.

De las distintas fechas nombradas anteriormente para marcar el inicio del movimiento, para Plemuu la fecha por excelencia es el 26 de enero de 1984, porque ese día los grupos barriales marcharon por la vereda de la calle 18 de Julio y luego de ese acto público se pusieron nombre: “(...) Eso fue el 26 de enero del 84. [en el diario] nos ponen que somos las madres, y no éramos las madres. Entonces nos pusimos el nombre Plemuu nosotras" (Integrante Plemuu, comunicación personal, 8 de febrero 2018).

La marcha de enero de 1984 está en el contexto de un llamado de huelga general del PIT y la reimposición de las medidas prontas de seguridad. Las mujeres amas de casa, desde sus grupos, tomaron la iniciativa de organizar una marcha silenciosa, porque les parecía que los hombres estaban aún miedosos (Johnson, 2000). La convocatoria fue "de boca en boca" y participaron más de 2000 mujeres, muchas de ellas no habían participado de otras acciones de protesta antes (Johnson, 2000). Era un contexto en el que movilizarse aún era riesgoso, el propio hecho de hacerlo por la vereda y no tomar la calle era parte de las formas de manifestarse pero con ciertos recaudos. 
Figura 3. Círculo de Estudios de la Mujer, Chile, 1938

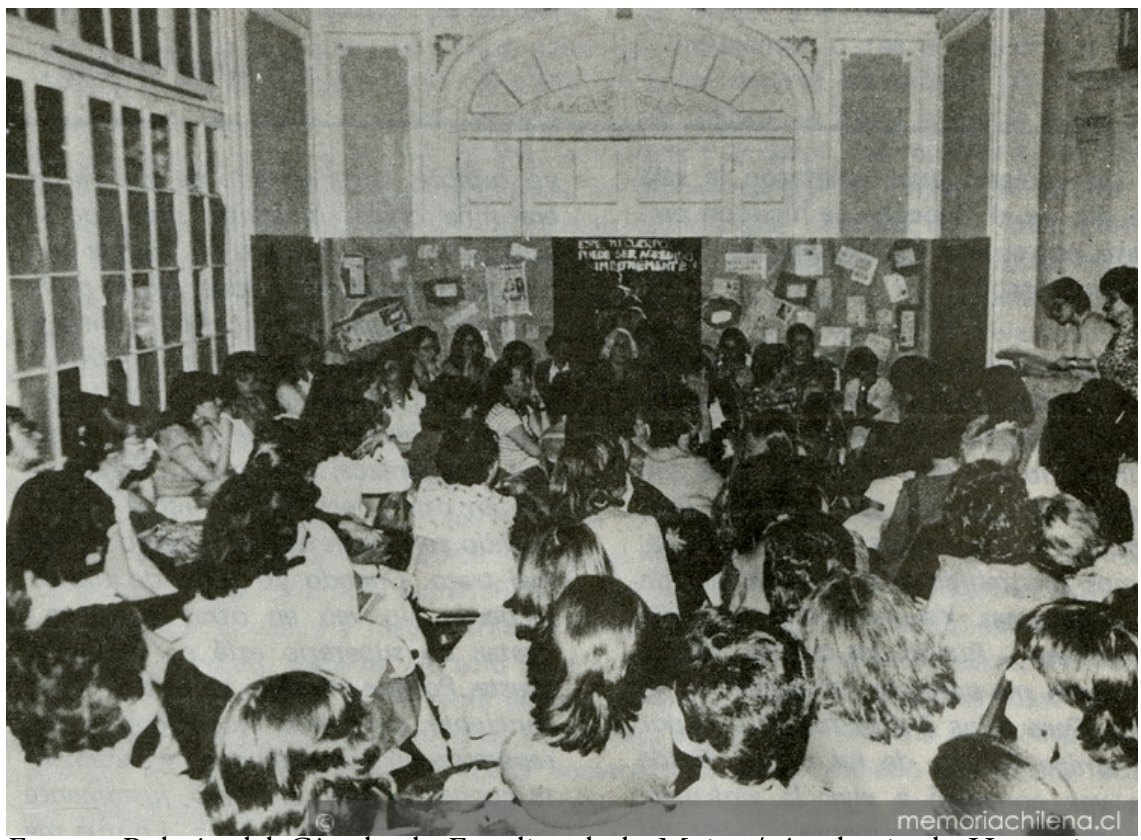

Fuente: Boletín del Círculo de Estudios de la Mujer / Academia de Humanismo Cristiano. Santiago: El Círculo, 1983- (Santiago: Icecoop) volúmenes, número 11, (enero 1983), p. 12. Tomado de la colección digital de la Biblioteca Nacional de Chile

El espacio de Plemuu reunía a mujeres diversas, no todas con experiencia previa de militancia y, en algunos casos, desde la imposibilidad o la incomodidad de los espacios mixtos de los que venían. Este encuentro en la diversidad era un desafío permanente. Asimismo tuvieron un lugar relevante en la articulación del movimiento, no únicamente por la diversidad que este albergaba, sino por su apuesta de hacer acciones públicas con otras. Llamarse plenario fue una aspiración de ser plurales, abiertas, heterogéneas y con aspiración a la horizontalidad. Ponerse nombre fue también la estrategia frente al sentimiento de que desde los grupos políticos partidarios o más más cercanos al sindicalismo no se cooptara la organización de mujeres. El debate sobre la autonomía va cobrando fuerza con los años. Plemuu se volvió una organización paraguas para grupos barriales, trabajadoras, estudiantes, académicas e integrantes de diversos partidos políticos. En los siguientes ańos fue siendo referente de varias articulaciones, y el punto máximo de esta tarea se realiza en 1985 en la 
coordinación de los documentos sobre la cuestión de la mujer presentados en la Concertación.

Las mujeres que crean Plemuu se reunieron inicialmente para decir basta a la represión, para resistir y colaborar en la reapertura democrática desde grupos barriales de mujeres. No era exclusivamente de mujeres que eran solo "amas de casa", puesto que también muchas de ellas eran trabajadoras asalariadas. Carmen Tornaría (1986) —una de sus fundadoras y la que más ha escrito sobre la experiencia - seńala que el auge del movimiento de mujeres y/o feminista a la salida a la dictadura tiene inicialmente un anclaje barrial y popular, nace de un entramado de mujeres organizadas desde dicha trama para resolver problemas cotidianos o sostener otras luchas. Se trata de mujeres organizadas por temas comunes como la vivienda, la educación de los hijos, la carestía, el trabajo, los derechos humanos y no necesariamente desde lo que Tornaría llama "conciencia de género" (1986, p.38).

Según Tornaría (1986) aparece una nueva política desde las prácticas de mujeres, en tanto aparecen nuevas formas de hacer y pensar lo político a partir de las experiencias concretas, en tanto la tradicional esfera del mundo político estaba bloqueada por la represión dictatorial. Para sortear la represión, e incluso dado el retraimiento de muchos hombres por esa misma razón, el hogar y el barrio se habían convertido en lugares privilegiados para las acciones de resistencia en dónde:

las mujeres éramos expertas en ese medio cuyas reglas y lealtades casi desconocían los hombres. Las respuestas desde la resistencia no solo involucran a las mujeres sino que asumen modalidades nuevas, vinculadas a lo doméstico -apagones, caceroleos, jornadas de no-compra, la práctica del "boca a boca" para transmitir información.(...) y, por último, lo fundamental- miles de mujeres hemos comenzado a cambiar y hemos construido nuestra identidad rompiendo viejos lazos de relación asimétrica y de poder en el espacio cotidiano, integrando a nuestras parejas e hijos al proyecto de cambiar la calidad de vida, miles de mujeres, con la fuerza que da el cambio tangible para trasladar ese proyecto a otros espacios a los que nos vinculamos (Tornaría, 1986, p.38-44).

Estas tramas son una de las partes constitutivas de las organizaciones de mujeres durante los años 80 , que frente a la profundización de la desigualdad social, muestran como contrapartida estrategias solidarias que se van tejiendo 
y que convierten al barrio como campo propicio para la politización de lo cotidiano en un contexto de participación barrial general. Esta resistencia por ejemplo se evidenciaba desde el recolectar ropa o alimentos para los presos políticos, a la realización de ollas populares para solventar la crisis (Giorgi, 2015; Sapriza, 2003). A la par que se gestaba esta trama para sostener la vida comienzan a politizarse las mujeres.

Los grupos barriales de mujeres estaban compuestos principalmente por amas de casa, aunque no exclusivamente, y las fue uniendo la idea de cambiar la organización de las familias a la par que luchaban por la democracia. La mayoría estaban en barrios de estratos medios y populares (Malvín, Cordón, Complejo Bulevar, Parque Posadas, Cerro, Sayago, Paso Molino, Villa Dolores), aunque en otros puntos del país había grupos también (Florida, Treinta y Tres, Canelones, Melo). En 1985 se organizó en Melo el primer encuentro de mujeres del interior, con participación de todos los grupos, la organización del mismo se coordinó desde Plemuu con Las Paulinas, un grupo de esa misma localidad. Los grupos se reunían en general una vez a la semana y luego realizaban coordinaciones periódicas. Un elemento interesante es el pasaje de amas de casa como elemento desvalorizado de su ser y su trabajo a la creciente valorización del mismo. En este pasaje fueron encontrando estrategias de lucha en lo cotidiano, apoyadas desde el sostén que los grupos de mujeres les brindaban. En la experiencia de los grupos de mujeres empezaban a problematizar su ser mujeres, y desde allí empezaban a ver con otros ojos a las otras mujeres con las que se iban encontrando, aunque no fueran de la organización.

Al reunirse y compartir sus necesidades y problemas comienzan a descubrir que no era asunto de una o de otra, sino de todas. A la par de resolver otros temas, comienzan a hablar de sexualidad, trabajo doméstico y maternidad. Existen varios registros de las actividades de algunos de los grupos, que dan cuenta de la inclusión de estas experiencias como parte del proceso de politización, en espacios que se asemejan a lo que las feministas de los 70 llamaban autoconciencia. Desde Plemuu a este tipo de actividades le llamaban "A partir de nosotras mismas" y fueron sistematizando tal experiencia en un cuadernillo homónimo, que usaron durante muchos años (Plemuu, 1986).

Como fue mencionado, además de la existencia de los grupos barriales desde Plemuu se dinamizó la formación del Grupo de Trabajo Condición de 
la Mujer en la Conapro. En los 80 se había creado la Intersocial, que reunía a las principales organizaciones sociales y luego la Intersectorial, integrada por los partidos políticos y el conjunto de la Intersocial (González, 2013). En ese contexto, el 17 de noviembre de 1984, Plemuu cita a otras organizaciones de mujeres y a mujeres de organizaciones sociales a una mesa sobre la condición de la mujer (Cotidiano Mujer, 1985). La Conapro se había establecido en agosto de 1984, y fue diseñada como espacio de articulación entre partidos políticos, organizaciones sociales y grupos de empresarios, para preparar la transición democrática desde mínimos consensos administrativos y programáticos (Johnson, 2003). Para algunos significaba consolidar la nueva democracia, para otros mitigar elementos del conflicto social (Johnson, 2003). Las mujeres entendieron que era un espacio para seńalar sus demandas y su modo de ver la política. Evidentemente ese grupo no fue bienvenido inicialmente, pero las mujeres decidieron ir de igual manera (Johnson, 2003). Una de las entrevistadas lo señala así:

Y se pide, las mujeres del frente piden para entrar en la concertación, para hacer una concertación de mujeres y les dicen que no. Entonces cuando les dicen que no, hablando ahí con ella decimos y por qué te tienen que decir que no y hacemos nosotras la convocatoria, que la hicimos en AEBU (Integrante Plemuu, comunicación personal, 8 de febrero 2018).

Finalmente unas 70 mujeres de 17 organizaciones comenzaron el grupo de trabajo pre-concertación sobre la condición de la mujer (Johnson, 2003). El Grupo de Trabajo sobre la Condición de la Mujer se instala formalmente el 27 de diciembre de 1984 (Cotidano Mujer, 1985) y logra en unas dos semanas cinco documentos sobre: Educación, Trabajo, Jurídico, Salud y Mujer y Participación. Si bien estos documentos fueron de poca relevancia para el nuevo partido en el gobierno, el Partido Colorado, para las mujeres — especialmente las de Plemuu - estos materiales siguieron relevantes. Realizaron con ellos unos materiales breves e ilustrados de difusión para realizar talleres o, como señala Johnson (2003), como elemento para la "concientización" sobre la situación de las mujeres. 


\section{Como breves son las flores. Reflexiones inacabadas, diálogos pendientes}

Si bien "en el país y en las casas" fue una consigna que tomaron todas, Kirkwood señala que el manifiesto en sí mismo expresaba más el discurso de las "feministas", no así el de las "políticas" que retomaran en los debates de los años 90 es sobre el énfasis o las prioridades de la lucha que se expresaba en el juego de las consignas "No hay democracia sin feminismo" y "No hay feminismo sin democracia" (Kirkwood, 1986). A nivel general para las "feministas" el énfasis era que no había democracia posible si no se resuelve el autoritarismo también a nivel privado, y para las "políticas" la urgencia era terminar el régimen pinochetista y luego luchar por las reivindicaciones de las mujeres. Parte de este debate en Chile permeó al resto del Cono Sur del mismo modo en que lo hizo la consigna.

Este mismo debate se hace más fuerte en los años 90, en tiempos de democracia formal y lo que esto suponía en lo que se refiere a la institucionalidad recuperada. Una vez echada a andar la nueva democracia, aparece "cierta sensación de estafa para las mujeres organizadas" (Tornaría, 1986 p.40) al retomarse los viejos canales de participación sindical y/o partidaria, lo que para muchas agregaba el mensaje "vuelvan a casa" (Tornaría,1985 p.10). Se señala como un momento confuso, crecen los problemas de coordinación y articulación y comienza a tensarse el debate sobre la autonomía en función de la nueva relación con el Estado y las políticas públicas.

Se señala como un momento de quiebre el Encuentro de Feminismos Latinoamericanos realizado en México en 1987, aunque tales debates tienen un punto álgido en 1993, durante en el VI Encuentro Feminista de El Salvador, que comienza a debatir la participación en Beijing y en el VII Encuentro Feminista. Es en Chile, en 1996, donde este conflicto se expresará de forma abierta. En estos debates, hay de trasfondo las ideas de los límites de la democracia y el cómo relacionarse con estas nuevas democracias y sus estructuras de poder, sobre el cómo se sigue la movilización callejera y la protesta en estos nuevos equilibrios.

Fruto de la lucha feminista a nivel internacional de las décadas previas, la reapertura democrática coincide con una fuerte canalización de recursos y el trazado de proyectos en diversos países con apoyo de las Naciones Unidas. Se

\footnotetext{
${ }^{11}$ Se llamaba "feministas" a aquellas que venían solo de la militancia feminista y "políticas" a las mujeres que también participaban en los partidos políticos (Kirkwood, 1986, p.193).
} 
empezaron a prever recursos presupuestales para desarrollar políticas sociales en materia de género lo que estableció una nueva forma de interacción entre el Estado y las organizaciones de mujeres, que en muchos casos devinieron en formato ONG (Organizaciones no gubernamentales). Una parte importante de las feministas veían en la institucionalidad posibilidades de avance para las mujeres en democracia y entendían que Beijing permitiera el respaldo para exigir a los gobiernos (Vargas, 2008). Careaga (2002) señala que tal institucionalización de los derechos de las mujeres quedó atrapada en la permanente tensión entre el horizonte utópico y lo políticamente posible.

Es en este nuevo momento del debate sobre la democracia, donde Margarita Pisano volverá a ser una de las feministas que escribe y publica posicionándose y cristalizando ciertos sentidos colectivos. Ella será una de las voces de referencia de lo que se conoce como feminismo autónomo. En sus textos y conferencias de ese momento rechaza tal inserción en "los espacios de poder masculinos" (Pisano, 2004; Pisano y Franulic, 2009) y el acceso de algunas feministas como representantes del movimiento feminista. Para Pisano los organismos internacionales y la institucionalidad democrática masculina dejaron al movimiento sin energía y capacidad creativa, lo que supuso el triunfo de la masculinidad y una funcionalización del feminismo.

Más allá de las huellas que aquí intento recoger, entiendo que el debate profundo sobre cómo se imaginaba la democracia para las feministas y lo que esto supuso en sus decisiones concretas está aún abierto. En cualquier caso pese a las diferencias y devenires, me ha interesado recuperar el tiempo feminista en que todas buscaron nombrar y entender mejor los sentidos de la democracia, por lo que esto supone para cambiar la vida. Se trataba de una democracia que estaba en crisis, que venía pisoteada, cuestionada, y de unas mujeres que venían de experimentar estar entre ellas (en las cárceles, en el exilio y luego en los espacios de mujeres y/ feministas) frente a las rupturas que las dictaduras supusieron para los espacios privados y políticos, frente a un conjunto de varones retraídos de los espacios por el terrorismo estatal. Un tiempo oscuro y extremadamente doloroso que paradójicamente abría los horizontes políticos. Un tiempo en que, en medio de dolor y muerte, el feminismo germinó con fuerza en el Cono Sur.

Estas experiencias de otras se entretejen con las nuestras, son un ensayo potente en el que no separamos nuestro cuerpo y nuestra experiencia histórica de las luchas que damos. En los últimos años, en Uruguay y en América 
Latina ha comenzado un nuevo accionar del movimiento feminista, que se ha entretejido desde las luchas contra las violencias contra las mujeres, y que también se ha canalizado desde el poner en palabras tales vivencias en espacios sólo entre mujeres. De forma similar a como se desató la lucha de las mujeres de generaciones anteriores, los catalizadores son los espacios propios de mujeres, el reencontrarnos con nosotras mismas. En ambos casos, se presentan como forma de autodefensa, en las luchas anteriores frente a la violencia desatada por el terrorismo de estado, en la actualidad como respuesta a los feminicidios. Son claramente contextos políticos diferentes, violencias diferenciales, pero en ambos casos, sirven como modo de decir "basta" y de ir creando otros modos políticos para vivir digna y colectivamente. Por ello siguen resonando las palabras que Julieta Kirkwood (1986) escribió al respecto de esos años: "lienzos/pancartas breves, como breves son las flores; feministas presas, golpeadas; escribimos, protestamos" porque aunque ese momento de lucha es de un tiempo breve en años, es un tiempo profundamente fértil y capaz de germinar en la actualidad de otros modos.

\section{Bibliografía citada}

Cardoso, Mónica, (2014) “Mujeres”. Revista Nuestro Tiempo, No 2, IMPO.

Careaga, Gloria, (2002) "Los estudios feministas en América Latina y el Caribe" En: Careaga, Gloria (coord.) Feminismos latinoamericanos: retos y perspectivas. Ciudad de México: UNAM- PUEG, pp. 89-109.

Cotidiano Mujer, (1985) "Con las feministas chilenas. Democracia en el país y en la casa”. Revista Cotidiano Mujer, Año I, Número 2, Octubre, p. 8.

Cotidiano Mujer, (1986a) "Político: un nudo a resolver" Revista Cotidiano Mujer, Año II, Número 9, Julio, p.1.

Cotidiano Mujer, (1986b) “¿Que aporta el feminismo a la política?” Revista Cotidiano Mujer, Año II, Número 9, Julio, p. 7.

Cotidiano Mujer, (1987) "En el IV Encuentro de mujeres de América Latina y el Caribe” Revista Cotidiano Mujer, Año II, Número 22, noviembre, p. 11. 

para una genealogía feminista...

Giorgi, Ana Laura, (2015) "A la calle con la cacerola. El encuentro entre la izquierda y el feminismo en los 80". Informe CLACSO. Buenos Aires. Recuperado de http://biblioteca.clacso.edu.ar/clacso/ becas/20150730114747/PLAVFDEGIORGI.pdf el 11 de noviembre de 2018.

González, Gustavo, (2013) Una historia de FUCVAM. Montevideo: Trilce

Gutiérrez Aguilar, Raquel; Sosa, Maria Noel; Reyes, Itandehui, (2018). "El entre mujeres como negación de las formas de interdependencia impuestas por el patriarcado capitalista y colonial. Reflexiones en torno a la violencia y la mediación patriarcal”, en Revista Heterotopias, Año 1, $\mathrm{N}^{\circ}$ 1, pp. 53-67.

Johnson, Niki, (2000) The right to have rights: Gender politics, citizenship and the state in Uruguay. Tesis para obtener el grado de Doctor, Departamento of political Studies, Queen Mary and Westfield College, University of London.

Kirkwood, Julieta, (1986) Ser politica en Chile. Las feministas y los partidos. Santiago de Chile: FLACSO.

Menéndez, Mariana, (2018) "Entre mujeres: Nuestro deseo de cambiarlo todo. Apuntes sobre el re-emerger feminista en el Río de la Plata". Revista El Apantle, No3 México: SOCCE.

Migliario, Alicia; Menéndez, Mariana; Blanco, Rossana, (2014) "Aquí estamos, hemos vuelto a nacer" Revista Escucharnos ecir, No1, julio. Bs.As/Montevideo: MPLD-Minervas.

Phillips, Anne, (1996) Género y teoría democrática. México: UNAM

Pisano, Margarita, (2004). Julia, quiero que seas feliz. Santiago de Chile: Lom Ediciones.

Pisano, Margarita y Franulic, Andrea, (2009) Una historia fuera de la historia: una biografía de Margarita Pisano. Santiago de Chile: Revolucionarias.

Plemuu, (1985) A partir de nosotras mismas. Cuaderno de trabajo. Montevideo: Plemuu.

Quijano, A., (2004) "El laberinto de America Latina: ¿hay otras salidas?”. Revista del Observatorio Social de América Latina,(13), pp. 15-30.

Restrepo, Alejandra, (2016) "La genealogía como método de investigación feminista”, en Blazquez Graf, Martha, Castañeda, Patricia (coords.) Lecturas críticas en investigación feminista. Ciudad de México: Red 

para una genealogía feminista...

Mexicana de Ciencia, Tecnología y Género/ Centro de Investigaciones Interdisciplinarias en Ciencias y Humanidades.

Rich, Adrienne, (1978). Nacemos de mujer. La maternidad como experiencia e institución. Madrid: Ediciones Cátedra/ Universitat de Valencia.

Rivera Garretas, María Milagros, (1997) El fraude de la igualdad. Los grandes desafíos del feminismo hoy. Buenos Aires: Librería de las mujeres.

Sapriza, Graciela, (2001) "Historia reciente de un sujeto con historia", en Revista Encuentros (7). Montevideo: Fundación de Cultura Universitaria.

Sapriza, Graciela, (2003) "Dueñas de la calle", en Revista Encuentros (7) p.8914.

Sapriza, Graciela, (2014) "Devenires del feminismo latino-uruguayo". En Revista Contrapunto 5, p.13-22. Montevideo: SCEAM,UdelaR.

Tarducci, Mónica y Deborah Rifkin, (2010) "Fragmentos de historia del feminismo en Argentina". En: Chaher, Sandra y Sonia Santoro (comps.). Las palabras tienen sexo II. Buenos Aires: Artemisa Comunicación.

Tessada Sepúlveda, Vanessa, (2013) “Democracia en el país y en la casa. Reflexión y activismo feminista durante la dictadura de Pinochet (1973-1989)" En: Cadernos Kóre. Revista de historia y pensamiento de género, Número 8, p. 96-117.

Tornaría, Carmen, (1985) Nuestro feminismo: Un proyecto de vida. Plemuu: Montevideo, 1985.

Tornaría, Carmen, (1986) La creación de una nueva dimensión de lo político a través de las prácticas de las mujeres. En: Seminario La Mujer Uruguaya hoy, s/d.

Vargas, Virginia, (2008) Feminismos en América Latina. Su aporte a la politica y a la democracia. Lima: Programa Democracia y Transformación Global /Centro de la Mujer Peruana Flora Tristán / Fondo Editorial de la Facultad de Ciencias Sociales-UNMSM. 